\title{
Gastric Perforation on an Intragastric Balloon: A Rare but Fatal Complication
}

\author{
Abderrahim Ait Abderrhim*, Hicham Bouhdouti, Karim Ibnmajdoub, Imane Toughrai, Khalid Maazaz
}

Department of Visceral Surgery B, University Hospital Center Hassan II of Fez in Morocco

DOI: $10.36347 /$ simcr.2020.v08i10.007

| Received: 13.09.2020 | Accepted: 21.09.2020 | Published: 15.10.2020

*Corresponding author: Abderrahim Ait Abderrhim

Abstract

Obesity is one of the most important public health issues due to its prevalence and associated complications. Endoscopic treatment with the introduction of an intragastric balloon (BIG) is a temporary aid that helps achieve weight loss and changes in eating habits. The results are encouraging in terms of weight loss and improvement of comorbidity factors; but this technique, despite being spectacular, still exposes it to serious and fatal complications such as gastric perforation by compression of the wall. Our article has well treated this complication in terms of its rarity; its severity and pathophysiology which makes our work interesting to improve endoscopic techniques of ballooning and modifies the monitoring times.

Keywords: Obesity, Endoscopic treatment, intragastric balloon, pathophysiology.

Copyright $(\mathcal{C} 2020$ The Author(s): This is an open-access article distributed under the terms of the Creative Commons Attribution 4.0 International License (CC BY-NC 4.0) which permits unrestricted use, distribution, and reproduction in any medium for non-commercial use provided the original author and source are credited.

\section{INTRODUCTION}

Obesity is a disease in its own right, which can lead to many complications affecting quality and life expectancy. It is now a real public health problem, particularly among young people. The treatment of morbid obesity is often surgical. The placement of an intragastric balloon may be a preliminary step to restrictive or bypass surgery. Complications of this endoscopic procedure are rare, represented mainly by nausea, vomiting and peptic esophagitis. Gastric perforation secondary to pyloric obstruction is an exceptional complication. We report a case of high occlusion by secondary pylore obstruction to an intragastric balloon, a review of the literature is also carried out.

\section{Case Presentation}

A 55-year-old woman who has a history of arterial hypertension controlled by calcium channel blockers, he also reports the notion of introducing an intra-gastric balloon for the treatment of morbid obesity. she goes to the emergency room for the management of vomiting with intense epigastric pain which goes back 24 hours before her admission, with an alteration of the general state, the clinical examination finds a patient obnubilée GCS at 13 , very dehydrated, shocked with a thready pulse and arterial tension at $9 / 6$, polypneic with respiratory rate 23 cycle $/ \mathrm{min}$, the abdominal examination finds a very distended abdomen tense with generalized sensitivity on all the abdomen , the hernial orifices are free and the rectal touch objective an empty rectal ampoule, the biological balance objectivait of the whites at 15000, a CRP at 200 and a hyponatremia at $125 \mathrm{meq}$, the rest of the ionogram, the liver balance, and the hemostasis parameters are normal, after the patient's hemodynamic and respiratory stabilization , an abdominal CT (A) was realized that objectified a huge stasis stomach reaching the secondary pelvis to pylor obstruction by the intragastric balloon.

There is also a small curvature enhancement defect with a large $5 \mathrm{~cm}$ puncture associated with pneumoperitoth, also a peritoneal effusion of high abundance.

Conservative measures were applied once the diagnosis was confirmed (nasogastric aspiration, infusion, intravenous, antispasmodic, proton pump inhibitors, antiemetics). Figure-1 median laparotomy is performed one hour later, with to exploration;

- Presence of a huge stasis stomach reaching the pelvis with palpation of an intragastric balloon landlocked at the pylor

- Presence also of a necrosis interesting the small curvature which includes a perforation measuring $6 \mathrm{~cm}$ Figure-2. 
- The surgical procedure consisted of a gastric emptying with extraction of balloon which is intact.

- A total gastrectomy was performed Figure-3.

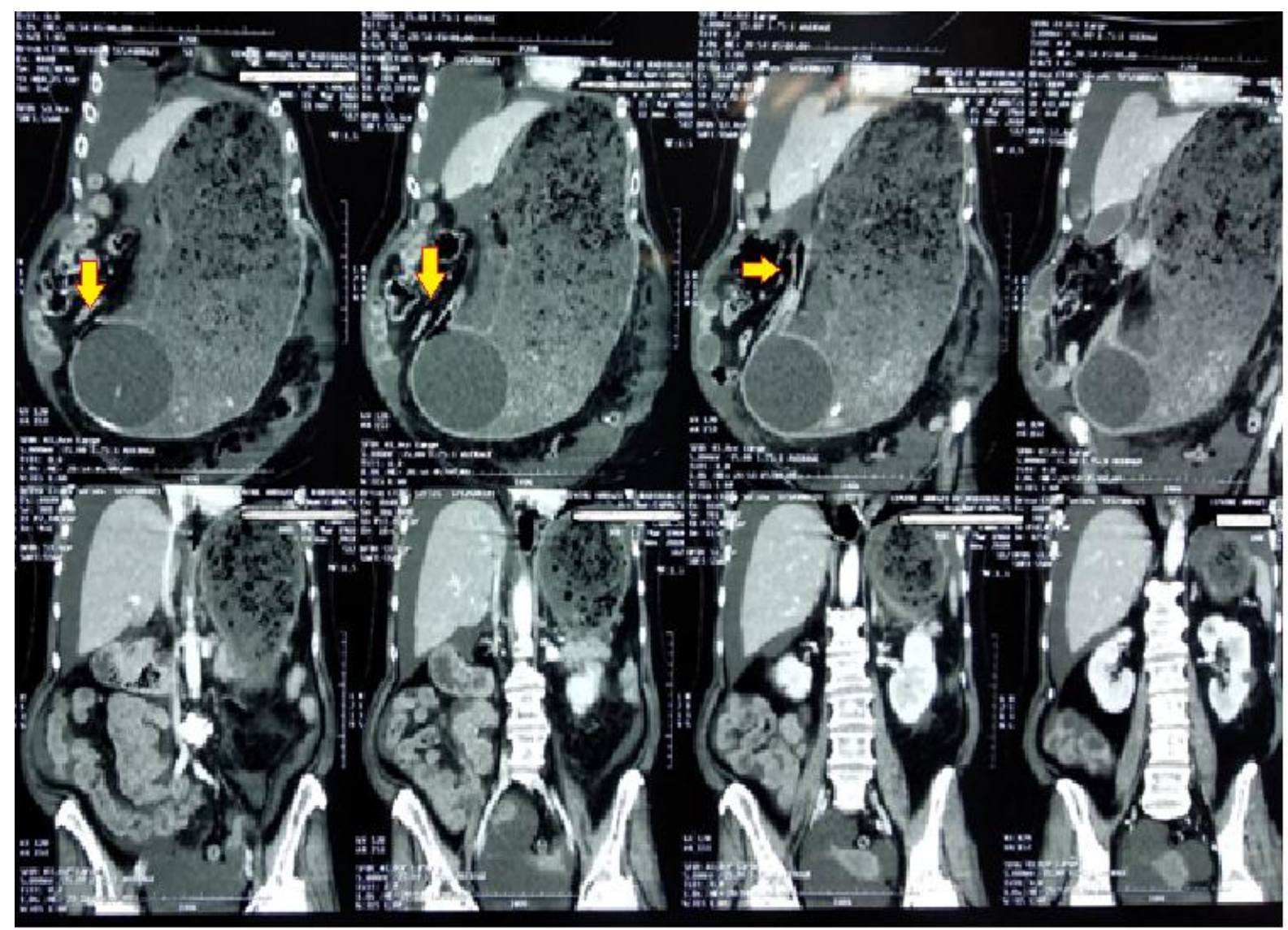

Fig-1: ABDOMINAL CT: objecting a necrosis of the small curvature that is perforated next to the balloon

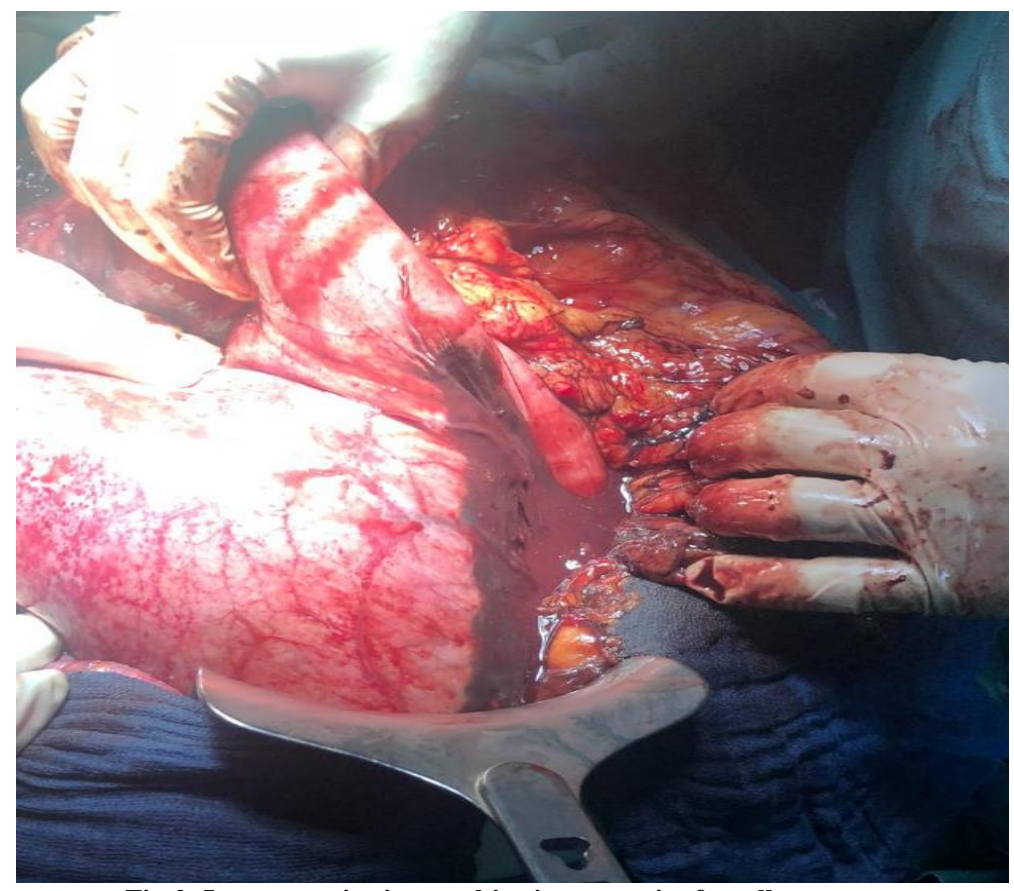

Fig-2: Intraoperative image objecting necrosis of small curvature 


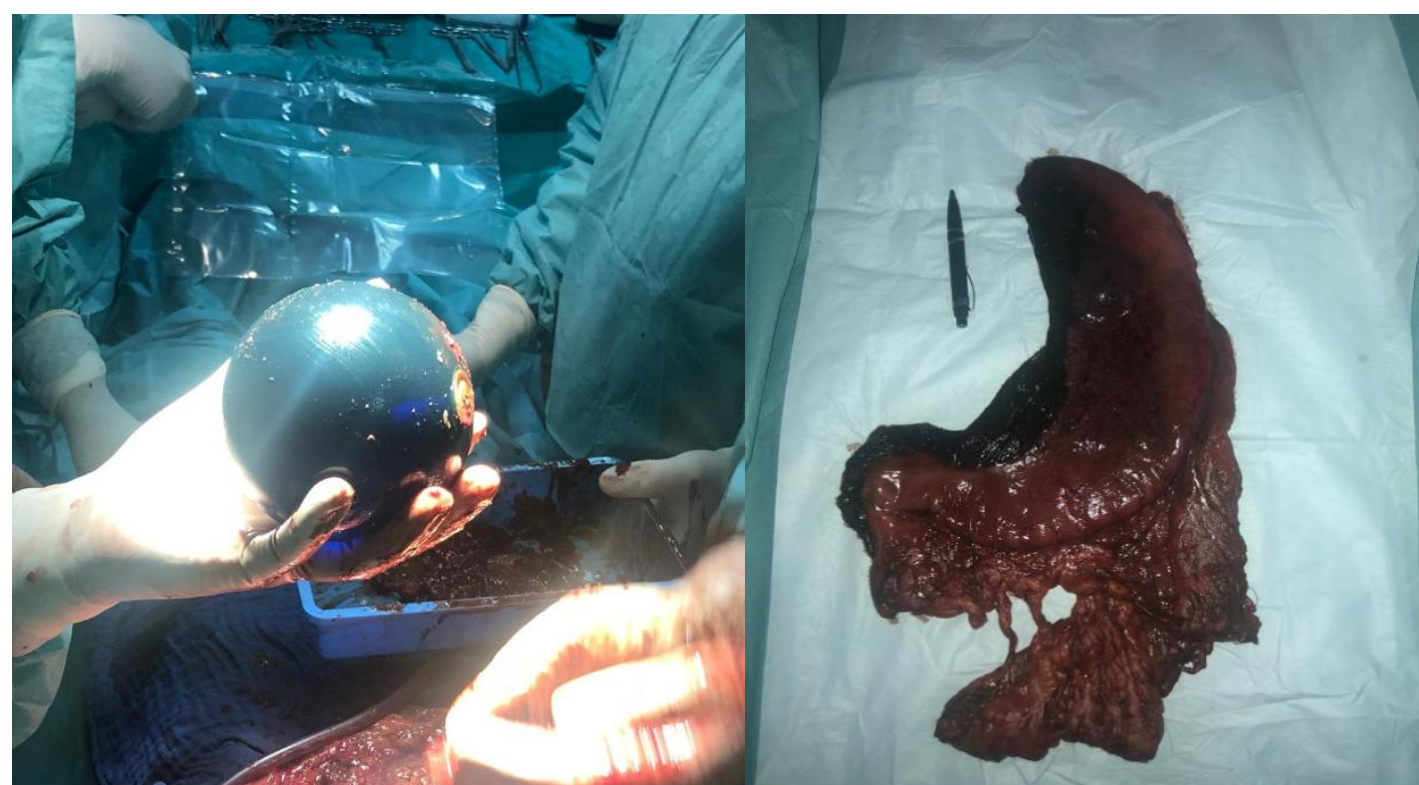

Fig-3: Image showing intragastric balloon (left image) and gastrectomy room (right image)

\section{DISCUSSION}

The implementation of a BIG for the treatment of obesity has been described since the early 1980s. The first results were published in 1982 [1]. This is a procedure that involves introducing an elastic balloon into the stomach in order to achieve an «artificial bezoar» to reduce appetite, food intake and induce weight loss.

The installation of a BIG is relatively noninvasive and reversible, its implementation being under endoscopic control. The application of a BIG is indicated in the treatment of morbid obesity in addition to dietary measures or as the first time in superobese patients before subsequent bariatric surgery $[2,3]$. At the beginning of their use, the silicone BIG were filled with a saline solution with a quantity of 400 to $700 \mathrm{ml}$. There are three types of BIG marketed. The two most used are left free in the gastric cavity and have an average volume of $500 \mathrm{ml}$ : one filled with water (Inamed Health®), the other inflated with air (Helioscopie ${ }^{\circledR}$ ). The third BIG (Districlass $®$ ) works according to a different principle: it is smaller in size $(200 \mathrm{ml})$ and fixed to the wall by an implantable chamber system that also allows the volume to be adjusted.

Since 2004, a new generation of BIG has appeared: made of silicone-coated polymer of the heliospher® type, filled with air with a volume between 650 and $750 \mathrm{ml}$ [4]. Most authors recommend removal of BIG six months after installation, regardless of effectiveness and weight. Our patient was 8 months away from the pose. She had been properly informed of the need to file the BIG at 6 months.
The efficacy and safety of BIG was evaluated in a meta-analysis [5] in 2008 involving 3,608 patients. The average weight loss at the end of treatment was $32.1 \%$ with a weight loss ranging from 10 to $19 \mathrm{~kg}$ on average over four to six months according to studies [716] and the average reduction in body mass index (BMI) of $5.7 \mathrm{~kg} / \mathrm{m} 2$. However, despite the importance of the number of people lost of sight, a significant part of the excess weight loss can be resumed one year after the end of treatment.

Milone et al., [16] compared the effect of the balloon to that of a sleeve gastrectomy before gastric bypass surgery in super-obese patients. Weight loss was significantly lower in the balloon group (22 versus 45 $\mathrm{kg}$ on average), but with significant resolution of comorbidities in $90 \%$ of patients in both groups. The symptoms most frequently encountered after a BIG are non-specific and innocuous, such as nausea, vomiting, cramping and abdominal pain in 10 to $90 \%$ of cases depending on the series, mainly during the first week [15]. More serious complications such as gastroduodenal ulcers and gastric dilations are more rarely described $[8,9]$.

Other serious complications were reported: Totté et al., [9] described two gastric perforations requiring laparotomy in a series of 126 patients. Gastric perforation can be fatal [10-12] especially in patients with a history of gastric surgery, leading authors to consider such a history as an absolute contraindication to BIG. Esophageal perforations have been described due to difficulties in laying [11] or extraction [12] of BIG. Cubattoli et al., [12] described a case of cardiac arrest becoming complicated by a vegetative state, by probable vagal stimulation a few hours after the pose of a BIG. 
A multitude of cases of migration of BIG following its rupture have been reported [14-16], causing obstructions of the small bowel, complete or incomplete, or even the colon [15], and requiring endoscopic or surgical extraction.

\section{Conclusion}

BIG is an endoscopic technique for the treatment of obesity whose long-term effectiveness remains to be evaluated. In practice, BIG can currently be included in the therapeutic arsenal of multidisciplinary groups specialized in the management of obesity, as an alternative or in preparation for bariatric surgery.

This technique exposes to complications, including surgery, as illustrated in this case of secondary gastric perforation has a pylor obstruction by BIG.

\section{REFERENCES}

1. Nieben OG, Harboe H. Intragastric balloon as an artificial bezoar for treatment of obesity. Lancet, 1982; 1:198-9.

2. Weiner A, Gutberlet H, Bockhorn H. Preparation of extremely obese patients for laparoscopic gastric banding by gastric balloon therapy. Obes Surg, 1999; 9:261-4.

3. De Waele B, Reynaert H, Urbain D, Willems G. Intragastric balloons for preoperative weight reduction. Obes Surg, 2000; 10:58-60.

4. Forestieri P, De Palma GD, Formato A, Giuliano ME, Monda A, Pilone V, Romano A, Tramontano $\mathrm{S}$. Heliosphere ${ }^{\circledR}$ bag in the treatment of severe obesity: preliminary experience. Obesity surgery. 2006 May 1;16(5):635-7.

5. Imaz I, Martínez-Cervell C, García-Álvarez EE, Sendra-Gutiérrez JM, González-Enríquez J. Safety and effectiveness of the intragastric balloon for obesity. A meta-analysis. Obesity surgery. 2008 Jul 1;18(7):841-846.

6. Lindor KD, Hughes Jr RW, Ilstrup DM, Jensen MD. Intragastric balloons in comparison with standard therapy for obesity - a randomized, double-blind trial. InMayo Clinic Proceedings 1987 Nov 1 (Vol. 62, No. 11, pp. 992-996). Elsevier.

7. Pretolesi F, Redaelli G, Papagni L, Derchi LE. Intragastric balloon for morbid obesity causing gastric dilatation. Eur Radiol. 2001; 11:588-9.

8. Totté E, Hendrckx L, Pauwels M, Van Hee R. Weight reduction by means of intragastric device: experience with the bioenterics intragastrique balloon. Obes Surg. 2006; 16:66770.

9. Genco A, Bruni T, Doldi SB, Forestieri P, Marino M, Busetto L, Giardiello C, Angrisani L, Pecchioli L, Stornelli P, Puglisi F. BioEnterics intragastric balloon: the Italian experience with 2,515 patients. Obesity surgery. 2005 Sep 1;15(8):1161-4.

10. Nijhof HW, Steenvoorde P, Tollenaar RA. Perforation of the esophagus caused by the insertion of an intragastric balloonfor the treatment of obesity. Obes Surg. 2006; 16:667-70.

11. Ruiz D, Vranas K, Robinson DA, Salvatore L, Turner JW, Addasi T. Esophageal perforation after gastric balloon extraction. Obesity surgery. 2009 Feb 1;19(2):257-60.

12. Cubattoli L, Barneschi C, Mastrocinque E, Bonucci P, Giomarelli PP. Cardiac arrest after intragastric balloon insertion in a super-obese patient. Obesity surgery. 2009 Feb 1;19(2):253-6.

13. Vanden Eynden F, Urbain P. Small intestine gastric balloon impacton treated by laparoscopic surgery. Obes Surg. 2001; 11:646-8.

14. Kim WY, Kirkpatrick UJ, Moody AP, Wake PN. Large bowel impaction by the bioenterics intragastric balloon necessitating surgical intervention. Ann R Coll Surg Engl, 2000; 82:202-204.

15. Mion F, Poncet G, Benatre V, Roman S, Napoléon B, Laville M. Place du ballon intragastrique dans la prise en charge de l'obésité. Hépato-Gastro \& Oncologie Digestive. 2008 Feb 10;15(1):43-8.

16. Milone L, Strong V, Gagner M. Laparoscopic sleeve gastrectomy is superior to endoscopic intragastric balloon as a first stage procedure for super-obese patients (BMI $\geq 50$ ). Obes Surg. 2005; 15:612-7. 